\title{
空気賦活による多孔性炭素の製造
}

\author{
安部有㚘，人見充則*，幾田信生，立本英機**，計良善也*
}

(平成7年 11 月 17 日受理)

\section{Production of Microporous Carbon by Air Activation}

\author{
Ikuo Abe, Mitsunori Hitomi*, Nobuo Ikuta, Hideki Tatsumoto**, Yoshiya Kera* \\ Osaka Municipal Technical Research Institute : Morinomiya 1-6-50, Joto-ku, \\ Osaka 536, Japan \\ *Department of Applied Chemistry, Faculty of Science and Engineering, \\ Kinki University, 3-4-1 Kowakae, Higashi-Osaka 577, Japan \\ **Department of Applied Chemistry, Faculty of Engineering, University of \\ Chiba, Yayoi-cho, Inage-ku, Chiba 263, Japan
}

Microporous carbons were produced by an activation using air from Japanese cypress charcoal. Effects of activation time, activation temperature, and air flow rate on the yield, porosity, and adsorption property of the microporous carbons were examined and the following results were obtained.

(1) The weight loss increases linearly with activation time.

(2) The formation efficiency of pore which has an adsorption ability increases with activation temperature.

(3) When the weight loss is above $95 \%$, the adsorption ability decreases.

(4) The activation efficiency increases with decreasing air flow rate.

(5) As activation temperature and air flow rate are constant, the specific surface area and mean pore diameter increase with activation time.

(6) As the specific surface area is constant, the mean pore diameter decreases with increasing activation temperature.

(7) The mean pore diameter increases with weight loss.

KEYWORDS : Microporous carbon, Activation, Activated carbon, Porosity, Pore-size distribution

\section{1. 緒 言}

代表的な多孔性炭素材料に活性炭や木炭がある。木炭は
木材を空気の少ない雾囲気で加熱することによって炭化し 製造する。この炭化過程において炭化炉中に存在する微量 の酸素が木炭の収率や細孔構造に影響を与える1)。活性炭

大阪市立工業研究所：テ536 大阪市城東区森ノ宮 1-6-50

* 近畿大学理工学部応用化学科: ₹ 577 東大阪市小若江 3-4-1

** 千葉大学工学部応用化学科： $\bar{\top} 260$ 千葉市稲毛区弥生町 1-33 
はヤシ款木炭やオガ屑を炭化した素灰などを原料とし, 水 蒸気賦活によって製造される。このとき水蒸気以外に空気 も賦活炉に導入し，空気中の酸素を賦活郕として利用する ことも行われている。すなわち賦活炉内では炭素と水蒸気 との反応, 炭素と酸素の反応 (燃焼反応), さらに燃焼反応 によって生じた二酸化炭素と炭素の反応などが起こってい る。

活性炭製造に関して水蒸気賦活や二酸化炭素賦活の研究 は多く行われてきたが2，3)，空気賦活に関する研究はほと んどなされていない。空気のみによる賦活の研究は活性炭 の製造だけでなく，木炭の製造にも深く関係しており重要 なものになると考えられる。そこで本研究では，ヒノキを 窒素ガス気流中で炭化した木炭を用いて空気賦活を行い, 得られる多孔性炭素の収率や細孔構造や吸着特性に及ほす 賦活時間, 賦活温度, 空気流量などの影響を調べた。

\section{2. 実験}

\section{1 原料木炭の製造方法}

市販されているヒノキ角材を約 $30 \times 30 \times 140 \mathrm{~mm} に$ 切り, 眞陽理化学器械株式会社製の内径 $115 \mathrm{~mm}$, 長さ $180 \mathrm{~mm}$ の ロータリーキルンに入れ, 窒素ガスを $0.5 \ell / \min$ の速度で流 しながら $5{ }^{\circ} \mathrm{C} / \mathrm{min}$ で $700{ }^{\circ} \mathrm{C}$ ま゙昇温し，この温度で 2 時間 保持したのち放冷し木炭を取り出した。賦活用試料にはこ の木炭を破砕し, 粒子径1.68～5.66mmにふるい分けした ものを使用した。

\section{2 空気賦活方法}

賦活に用いた装置は炭化に用いた装置と同じロータリー キルンである。賦活は原料木炭の仕込量を $10 \mathrm{~g}$ に固定し, 賦活温度を $750 \sim 950{ }^{\circ} \mathrm{C}$ 範囲で, 賦活時間を $15 \sim 168$ 分 の範囲で, 空気流速を $0.5 \sim 1.5 \ell / \mathrm{min}$ の範囲で変えて行った。

\section{3 ベンゼン蒸気吸着性能試験法}

製造した多孔性炭素の気相に打ける吸着性能を調べるた めに, 日本工業規格JIS K1474 活性炭試験方法に準じて, $25^{\circ} \mathrm{C}$ における $1 / 10$ 飽和度のベンゼン蒸気の吸着量を測定し た。吸着時間は 3 時間で行った。

\section{4 細孔構造特性の測定法}

製造した多孔性炭素について, 日本べル株式会社製BELSORP28-SA 型を用いて液体窒素温度における窒素ガスの 吸着等温線を測定した。比表面積は相対圧 $0.01 \sim 0.15$ の範 囲でBET プロットを行うことにより求め4), 細孔径分布曲 線はCranston-Inkley 法5) で求めた。

\section{3. 結果および考察}

\section{1 空気賦活による多孔性炭素の製造}

賦活温度や賦活時間や空気流速を変えて空気賦活を行い 種々の多孔性炭素を製造した。賦活条件と収率などの結果
を Table 1 に示す。

一般に空気中の酸素と炭素の反応は次式で表される6)。

$$
\begin{aligned}
& \mathrm{C}+\mathrm{O}_{2}=\mathrm{CO}_{2}+94.0 \mathrm{kcal} \\
& 2 \mathrm{C}+\mathrm{O}_{2}=2 \mathrm{CO}+53.2 \mathrm{kcal}
\end{aligned}
$$

（1）式と（2）式は発熱反応であり一般的な燃焼反応である。 また，このほかにも（1）式で生成した二酸化炭素がさらに 炭素と反応する次式も考えられる。

$$
\mathrm{C}+\mathrm{CO}_{2}=2 \mathrm{CO}-40.8 \mathrm{kcal}
$$

（3）式は吸熱反応である。

Fig.1 に賦活時間と重量減少率の関係を示す。重量減少率 は賦活時間の増加とともにほほ直線的に増加した。直線の 傾き（重量減少速度を表している）は賦活温度が高くなる ほど，空気流速が速くなるほど大きくなった。Fig.1に表さ れた結果は（1），(2），(3）式で示される反応などが合さ った結果であり，この結果だけではそれぞれの割合は分か らない。Fig.1 から, 賦活温度 $850^{\circ} \mathrm{C}$, 空気流速 $1.5 \ell / \min$ の ときの傾きと賦活温度 $950{ }^{\circ} \mathrm{C}$, 空気流速 $1.0 \ell / \mathrm{min}$ のときの 傾きがほほ同じであることがわかるが, この結果は空気流 速を $0.5 \ell / \mathrm{min}$ 増加させたときの効果と賦活温度を $100{ }^{\circ} \mathrm{C}$ 上 昇させたときの効果とがほほ同じであったことを示す。

\section{2 賦活条件と吸着性能の関係}

空気流速を $1.0 \ell / \mathrm{min}$ とし, 賦活温度を変えたときの重量 減少率とベンゼン蒸気吸着性能の関係を Fig.2 に示す。同じ 重量減少率であっても賦活温度が高いほどベンゼン蒸気吸 着性能が高くなった。すなわち賦活温度が高いほど効率よ く吸着能力を有する細孔を生成したことになる。(3) 式の 反応は二酸化炭素賦活の主反応であるが，この反応は

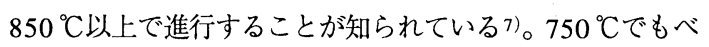
ンゼン蒝気の吸着量が増加することから燃焼反応でも量は 少ないが細孔を生成することがわかる。

重量減少率が約 $95 \%$ 以上になると吸着性能が低下寸る傾 向が見られた。この原因として過度の賦活による細孔の破 壊と灰分含有率の増加が考えられる。

つぎに，賦活温度を $850^{\circ} \mathrm{C}$ と，空気流速を変えたとき の重量減少率とベンゼン蒸気吸着性能の関係を Fig.3に示 す。空気流速が $0.5 \ell / \mathrm{min}$ のときが最も効率よく賦活され, 空気流速が速くなるにつれて効率が低下したが, $1.0 \ell / \mathrm{min}$ と $1.5 \ell / \mathrm{min}$ は同程度であった。空気流速が遅くなるほど賦 活効率が高くなった理由として，賦活の主反応である（3） の反応速度が遅いことが考えられる8)。

\section{3 賦活条件と細孔構造の関係}

空気流速を $1.0 \ell / \mathrm{min}$, 賦活時間を 60 分とし, 賦活温度を 変えて製造した多孔性炭素の細孔径分布曲線を Fig.4 に示 
Table 1 Activation condition and adsorptive properties of porous carbons.

\begin{tabular}{|c|c|c|c|c|c|c|c|c|c|}
\hline $\begin{array}{c}\text { Carbon } \\
\text { No. }\end{array}$ & $\begin{array}{c}\text { Activation } \\
\text { temperature } \\
\left({ }^{\circ} \mathrm{C}\right) \\
\end{array}$ & $\begin{array}{l}\text { Air flow } \\
\text { rate } \\
(\ell / \mathrm{min}) \\
\end{array}$ & $\begin{array}{l}\text { Activation } \\
\text { time } \\
\text { (min) }\end{array}$ & $(\%)$ & $\begin{array}{l}\text { Weight } \\
\text { loss } \\
(\%) \\
\end{array}$ & $\begin{array}{l}\text { Specific } \\
\text { surface } \\
\text { area } \\
S\left(\mathrm{~m}^{2} / \mathrm{g}\right) \\
\end{array}$ & $\begin{array}{l}\begin{array}{l}\text { Pore } \\
\text { volume }\end{array} \\
V(\mathrm{ml} / \mathrm{g}) \\
\end{array}$ & $\begin{array}{l}\text { Mean pore } \\
\text { diameter } \\
D(\mathrm{~nm})\end{array}$ & $\begin{array}{l}\text { Benzeme } \\
\text { adsorption } \\
\text { capacity } \\
\text { (wt\%) }\end{array}$ \\
\hline [1] & - & - & - & - & - & 369 & 0.072 & 0.78 & 6.5 \\
\hline [2] & 750 & 1.0 & 30 & 66.0 & 34.0 & 540 & 0.162 & 1.20 & 14.5 \\
\hline [3] & 750 & 1.0 & 60 & 43.0 & 57.0 & 570 & 0.161 & 1.13 & 15.8 \\
\hline [4] & 750 & 1.0 & 90 & 15.8 & 84.2 & 578 & 0.147 & 1.02 & 16.2 \\
\hline [5] & 750 & 1.0 & 96 & 2.4 & 97.6 & - & - & - & 12.1 \\
\hline [6] & 850 & 1.0 & 15 & 75.0 & 25.0 & 596 & 0.110 & 0.74 & 16.5 \\
\hline [7] & 850 & 1.0 & 30 & 57.4 & 42.6 & 626 & 0.158 & 1.01 & 21.1 \\
\hline [8] & 850 & 1.0 & 45 & 39.7 & 60.3 & 895 & 0.216 & 0.97 & 25.6 \\
\hline [9] & 850 & 1.0 & 60 & 31.7 & 68.3 & 949 & 0.229 & 0.97 & 31.7 \\
\hline [10] & 850 & 1.0 & 90 & 12.0 & 88.0 & 1212 & 0.362 & 1.19 & 33.4 \\
\hline [11] & 850 & 1.0 & 96 & 2.2 & 97.8 & 35 & 0.070 & 8.00 & 6.5 \\
\hline [12] & 950 & 1.0 & 15 & 70.6 & 29.4 & - & - & - & 19.2 \\
\hline [13] & 950 & 1.0 & 30 & 51.0 & 49.0 & 1022 & 0.206 & 0.81 & 31.9 \\
\hline [14] & 950 & 1.0 & 45 & 33.7 & 66.3 & 1368 & 0.401 & 1.17 & 40.6 \\
\hline [15] & 950 & 1.0 & 60 & 27.5 & 72.5 & 1500 & 0.455 & 1.21 & 42.0 \\
\hline [16] & 950 & 1.0 & 66 & 9.2 & 90.8 & 1814 & 0.679 & 1.50 & 56.5 \\
\hline [17] & 950 & 1.0 & 69 & 4.2 & 95.8 & - & - & - & 52.2 \\
\hline [18] & 850 & 0.5 & 30 & 78.2 & 21.8 & 587 & 0.084 & 0.57 & 16.7 \\
\hline [19] & 850 & 0.5 & 60 & 62.1 & 37.9 & 790 & 0.214 & 1.08 & 23.9 \\
\hline [20] & 850 & 0.5 & 90 & 54.0 & 46.0 & 998 & 0.235 & 0.94 & 29.6 \\
\hline [21] & 850 & 0.5 & 120 & 25.0 & 75.0 & - & - & - & 39.5 \\
\hline [22] & 850 & 0.5 & 135 & 18.0 & 82.0 & - & - & - & 44.2 \\
\hline [23] & 850 & 0.5 & 150 & 7.8 & 92.2 & - & - & - & 47.6 \\
\hline [24] & 850 & 0.5 & 168 & 6.5 & 93.5 & - & - & - & 40.0 \\
\hline [25] & 850 & 1.5 & 15 & 63.6 & 36.4 & - & - & - & 17.8 \\
\hline [26] & 850 & 1.5 & 30 & 54.5 & 45.5 & 719 & 0.137 & 0.76 & 21.0 \\
\hline$[27]$ & 850 & 1.5 & 42 & 37.6 & 62.4 & - & - & - & 27.3 \\
\hline [28] & 850 & 1.5 & 60 & 15.7 & 84.3 & - & - & - & 34.2 \\
\hline [29] & 850 & 1.5 & 66 & 4.5 & 95.5 & - & - & - & 28.1 \\
\hline
\end{tabular}

す。賦活温度が $750{ }^{\circ} \mathrm{C}$ のき半径 $1 \mathrm{~nm}$ 以上の範囲の細孔が 増加し $1 \mathrm{~nm}$ 以下の細孔が減少した。このことは燃焼反応は メソ孔を生成し，マイクロ孔を減少させることを示してい る。したがって, Fig.2で見られた $750{ }^{\circ} \mathrm{C}$ 賦活炭へのベンゼ ン蒸気吸着量の増加はおもにメソ孔への吸着であることが わかる。一方 $950{ }^{\circ} \mathrm{C}$ 賦活炭では $1 \mathrm{~nm}$ 以下の細孔が大幅に増 加しており，二酸化炭素による賦活反応がマイクロ孔の生 成に大きく寄与していることがわかる。

Table 1 に多孔性炭素の比表面積 $S\left(\mathrm{~m}^{2} / \mathrm{g}\right)$ と細孔容積 $V$ $(\mathrm{ml} / \mathrm{g})$ の值を示す。また, 次式9)により $S$ と $V$ から計算し た平均細孔直径 $D(\mathrm{~nm})$ も示す。

$$
D=4000 \mathrm{~V} / \mathrm{S}
$$

比表面積および細孔容積の值はベンゼン蒸気吸着性能と 同様の傾向を示し, 重量減少率の増加に伴い比表面積およ

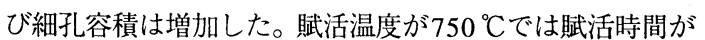
90 分で比表面積が $578 \mathrm{~m}^{2} / \mathrm{g}$ と小さいが, $950{ }^{\circ} \mathrm{C} て ゙ は 66$ 分で も $1814 \mathrm{~m}^{2} / \mathrm{g}$ になったこのように空気賦活法によっても条 件がよければ高表面積の活性炭を製造できることがわかる。

比表面積と平均細孔直径の関係を Fig.5に示す。ここで, 重量減少が95\%以上の多孔性炭素のデー夕は灰分の影響を 大きく受けているため除外した。賦活温度と空気流速が同 じであれば，賦活時間が長くなるほど比表面積が大きくな り平均細孔直径が大きくなる傾向が見られた。空気流速が $1.0 \ell / \mathrm{min}$ のとき, 賦活温度が高くなるほど同じ比表面積で あっても平均細孔直径が小さくなった。この結果に対して 別の見方をすると, 賦活温度が高くなるほど同じ比表面積 を得るために必要な賦活時間は短くなっており，賦活時間 が短くなるほど平均細孔直径が小さくなることを表してい る。この傾向は水蒸気賦活反応と同じであり，賦活時間が 


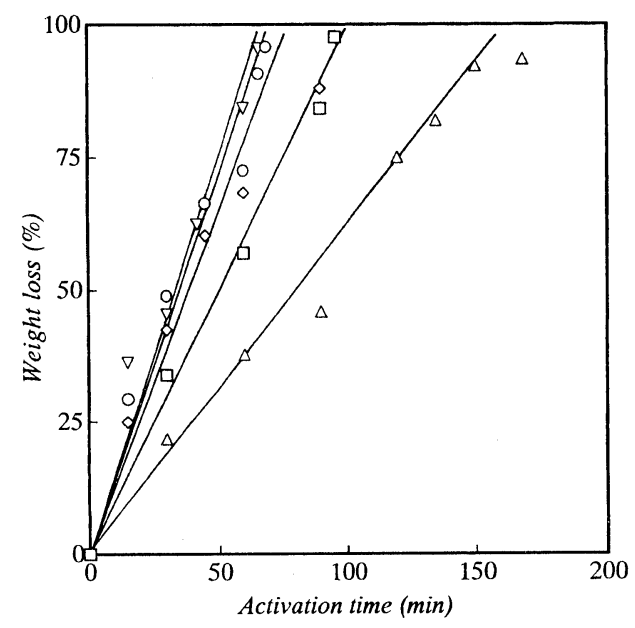

Fig.1 Relationship between activation time and weight loss in several activation conditions;

$\square: 750{ }^{\circ} \mathrm{C}, 1.0 \ell / \mathrm{min}, \diamond: 850^{\circ} \mathrm{C}, 1.0 \ell / \mathrm{min}$,

$\bigcirc: 950^{\circ} \mathrm{C}, 1.0 \ell / \mathrm{min}$,

$\triangle: 850^{\circ} \mathrm{C}, 0.5 \ell / \mathrm{min}, \nabla: 850^{\circ} \mathrm{C}, 1.5 \ell / \mathrm{min}$.

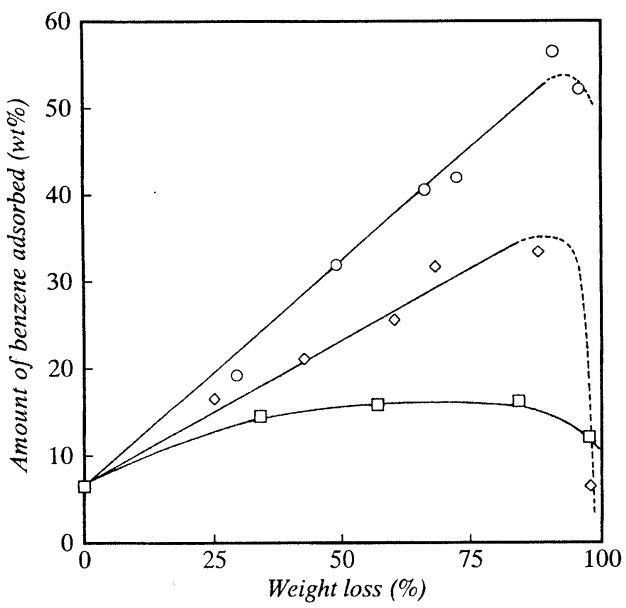

Fig.2 Relationship between weight loss and amount of benzene adsorbed for specimens activated at an air flow rate of $1.0 \ell / \mathrm{min}$ and several activation temperatures;

$\square: 750{ }^{\circ} \mathrm{C}, \diamond: 850{ }^{\circ} \mathrm{C}, \bigcirc: 950{ }^{\circ} \mathrm{C}$.

長くなると生成するマイクロ孔の数が増加し, 隣接するマ イクロ孔との間隔が狭くなり，さらに賦活が進むとマイク 口孔同士の合一が起こりだし細孔径が大きくなる。

重量減少率と平均細孔直径の関係を Fig.6に示す。大ま

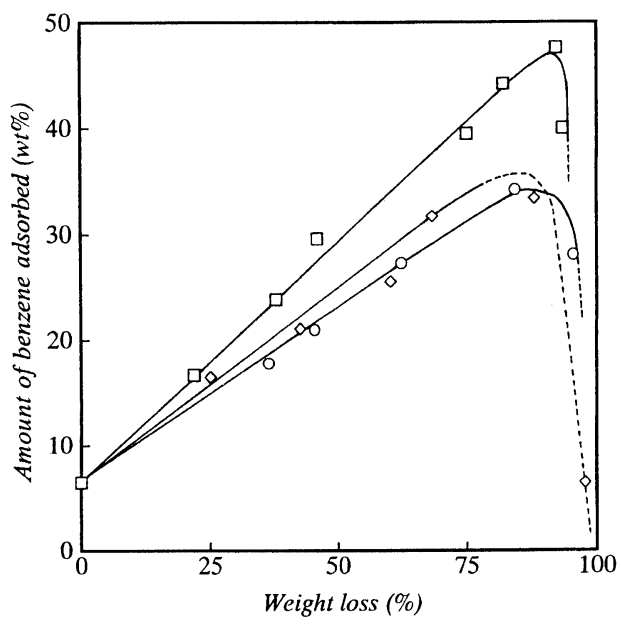

Fig.3 Relationship between weight loss and amount of benzene adsorbed for specimens activated at $850{ }^{\circ} \mathrm{C}$ and several air flow rates;

$\square: 0.5 \ell / \mathrm{min}, \diamond: 1.0 \ell / \mathrm{min}, \bigcirc: 1.5 \ell / \mathrm{min}$.

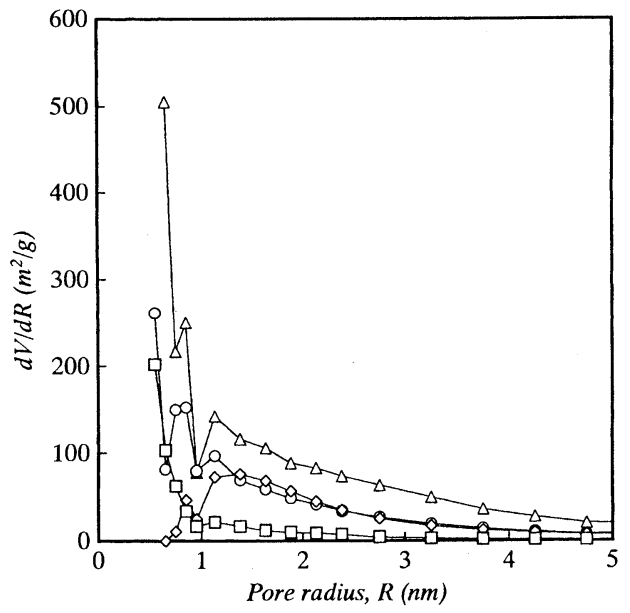

Fig.4 Pore-size distribution calculated from adsorption isotherm of nitrogen for specimens activated for $60 \mathrm{~min}$ at an air flow rate of $1.0 \ell / \mathrm{min}$ and several activation temperatures;

$\square$ : Raw material, $\diamond: 750{ }^{\circ} \mathrm{C}, \bigcirc: 850^{\circ} \mathrm{C}$, $\triangle: 950^{\circ} \mathrm{C}$.

かであるが，重量減少率が増加すると平均細孔直径も増加

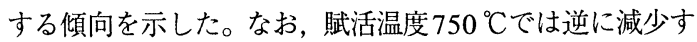
る傾向が見られたが，この原因は明らかでない。 


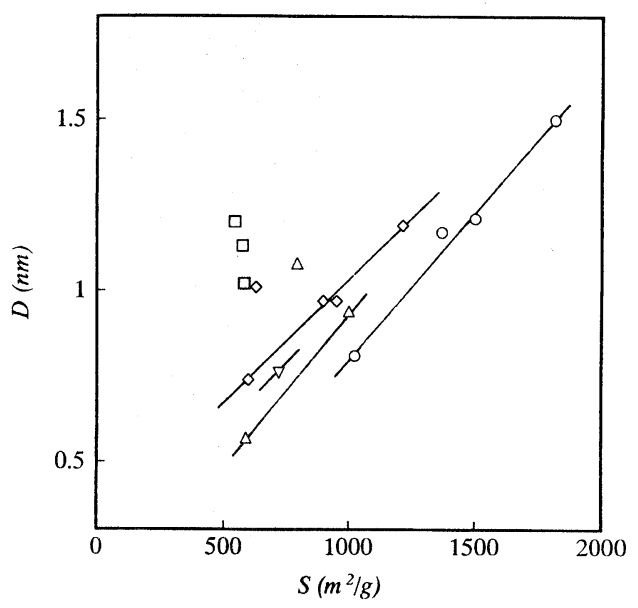

Fig.5 Relationship between specific surface area and mean pore diameter in several activation conditions;

$$
\begin{aligned}
& \square: 750{ }^{\circ} \mathrm{C}, 1.0 \ell / \mathrm{min}, \diamond: 850^{\circ} \mathrm{C}, 1.0 \ell / \mathrm{min}, \\
& \bigcirc: 950^{\circ} \mathrm{C}, 1.0 \ell / \mathrm{min}, \\
& \triangle: 850^{\circ} \mathrm{C}, 0.5 \ell / \mathrm{min}, \nabla: 850^{\circ} \mathrm{C}, 1.5 \ell / \mathrm{min} .
\end{aligned}
$$

\section{4. まとめ}

ヒノキ木炭を原料にして空気賦活を行い，得られる多孔 性炭素の収率，細孔構造，吸着特性に及ほす賦活時間，賦 活温度，空気流量などの影響を調べ，以下の知見を得た。

(1) 重量減少率は賦活時間の増加とともにほほ直線的に増 加する。

(2) 賦活温度が高くなるほど効率よく吸着能力を有する細 孔を生成する。

（3）重量減少率が約 $95 \%$ 以上になると吸着性能が低下する 傾向が見られる。

（4）空気流速が遅くなるほど効率よく賦活される。

（5）賦活温度と空気流速が同じであれば，賦活時間が長く なるほど比表面積が大きくなり平均細孔直径が大きくなる。

（6）同じ比表面積であっても賦活温度が高くなるほど平均 細孔直径が小さくなる。

（7）重量減少率が増加すると平均細孔直径は増加する。

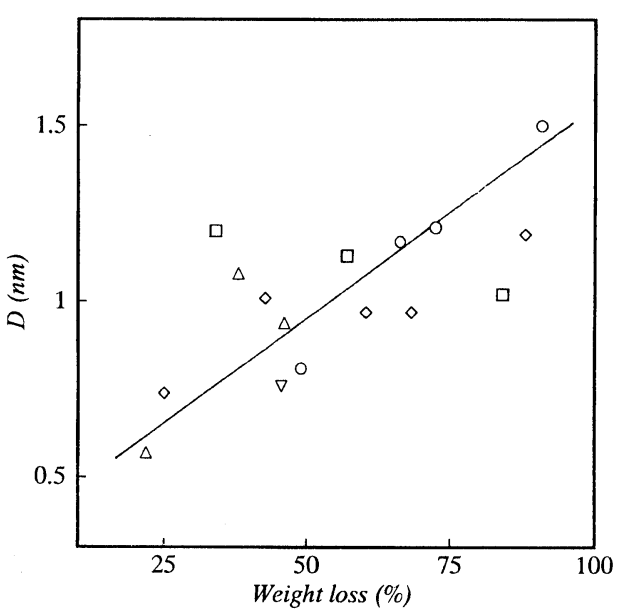

Fig.6 Relationship between weight loss and mean pore diameter in several activation conditions;

$$
\begin{aligned}
& \square: 750{ }^{\circ} \mathrm{C}, 1.0 \ell / \mathrm{min}, \diamond: 850^{\circ} \mathrm{C}, 1.0 \ell / \mathrm{min}, \\
& \mathrm{O}: 950{ }^{\circ} \mathrm{C}, 1.0 \ell / \mathrm{min}, \\
& \triangle: 850{ }^{\circ} \mathrm{C}, 0.5 \ell / \mathrm{min}, \nabla: 850^{\circ} \mathrm{C}, 1.5 \ell / \mathrm{min} .
\end{aligned}
$$

\section{文献}

1）安部有夫, 人見充則, 幾田信生, 川舟功朗, 計良善也, 炭素 1996 [No.171] 18-23.

2) J. W. Hassler, Activated Carbon, p.174, Chemical Publishing Company, New York (1963).

3）北川睦夫, 柳井 弘, 江口良友, 国部 進, 活性炭工 業, p.24, 重化学工業通信社（1974）.

4）安部郁夫, Chem. Express 7 (1982）97-100.

5) R. W. Cranston and F. A. Inkley, Adv. in Catalysis 9 (1957) 143-154.

6）真田雄三，鈴木基之，藤元 薰, “新版 活性炭一基礎 と応用一”, p.49, 講談社（1992）。

7）真田雄三, 鈴木基之, 藤元 薰, “新版 活性炭一基礎 と応用一”, p.48，講談社（1992）。

8) P. L. Walker, Jr., F. Rusinko, Jr. and L. G. Austin, Advances in Catalysis, Vol.11, Academic Press (1959).

9) S. J. Gregg, K. S. W. Sing, Adsorption, Surface Area, and Porosity, Academic Press (1967). 